\title{
The Impact of Cognitive-Behavioral Group Psycho-Education Program on Psychological Resilience, Irrational Beliefs, and Well-Being
}

\author{
Hatice Şahin ${ }^{1} \cdot$ Fulya Türk ${ }^{2}$ (D) \\ Published online: 1 April 2021 \\ (๑) The Author(s), under exclusive licence to Springer Science+Business Media, LLC, part of Springer Nature \\ 2021
}

\begin{abstract}
The aim of this study is to investigate the effect of cognitive-behavioral group psycho-education program on psychological resilience, irrational beliefs, and wellbeing. In the study, 29 high school students participated. As a data collection, The Resilience Scale, the Irrational Beliefs Scale-Adlescent Form, the Subjective Wellbeing Scale-High School Form and The Determination of Risk Factors were used. In the study, psycho-education program based on cognitive behavioral approach was applied to experimental group in 10 sessions, once a week. No study was performed with the control group. $2 \times 3$ experimental design was used in the research. The posttest was administered after the research was completed and follow-up measurements were performed five months later. As a result of the analyzes, it is concluded that there is an increase in psychological resilience levels and a decrease in irrational belief levels of students who participated in psycho-education program based on cognitive behavioral approach. It is concluded that there isn't change in the subjective well-being of the students before and after the application.
\end{abstract}

Keywords Psychological resilience $\cdot$ Cognitive behavioral · Psycho-education · Irrational beliefs $\cdot$ Subjective well-being $\cdot$ High school students

Fulya Türk

fulyaturk80@gmail.com

Hatice Şahin

htcgykkmrs@gmail.com

1 Karacaoglan Secondary School, Karatas District, Kahramanmaras, Turkey

2 Deparment of Guidance and Psychological Counseling, Faculty of Education Sciences, Istanbul Medeniyet University, Atalar, Şht. Hakan Kurban Avenue. No: 44, 34862 Kartal, İstanbul, Turkey 


\section{Introduction}

Difficult life situations affect almost all people even if at varying levels thus disrupting their adaptation process and mental health. Some people may be insufficient with regard to attention, love and opportunities when they encounter a problem, while others may remain standing despite all kinds of difficult conditions finding the power to overcome the problem in themselves and in their environment and most importantly they can continue on their path in a successful manner. Indeed, they recollect themselves undauntedly in the face of difficulties and continue their lives even stronger than before. The only foundation of these people who face difficult conditions in their lives is themselves. Perhaps, the question that should be asked at this point is this: How can these people accomplish all this?

The concept of resilience emerged during the 1970s as a result of studies on child development and psychopathology (Masten, 2001). Resilience has a wide range of meanings such as putting off traumatic experiences, overcoming difficulties in order to be successful in life and tolerating stress to function well in the duties of life (Masten \& Gewirtz, 2006). Psychological resilience is the ability of the individual to acquire good results despite severe risk factors that may have an impact on the development and adaptation of individuals (Luthar \& Cicchetti, 2000; Masten, 2001; Masten et al., 1990). Masten (2001) defines psychological resilience as an ordinary miracle, because resilience is made up of ordinary resources and processes. Psychological resilience is not a personality trait (Luthar \& Cicchetti, 2000; Masten, 2001, 2014). Two prerequisites are necessary in order to talk about the concept of resilience. The first is the presence of a high risk and the second is the ability to adapt (Masten \& Coatsworth, 1998; Masten \& Reed, 2002). Hence, it is difficult to state whether resilience is present or not for situations with no risk factor. Indeed, Luthar et al. (2000) have emphasized that the risk is a key factor and that when an individual is successful without facing difficult life experiences, this is not resilience but success.

There are three important aspects regarding the operational definition of psychological resilience. These are protective factors, risk factors and positive outcomes.

Risk Factors Masten and Reed (2002) emphasized that children who acquire positive outcomes in situations without risk can be called "accommodating" but not resilient. Risk factors for emotional and behavioral problems are; genetic risks, being subject to stressful living experiences (divorce, abuse, war etc.) and situations related with living conditions (low socio-economic level, low education level) (Masten, 2014; Masten \& Reed, 2002). Innate diseases and low birth weight are among important genetic risk factors (Masten, 2014; Zolkoski \& Bullock, 2012). Whereas environmental risk factors have been defined as; negative life events (Masten, 2014), family conflicts (Brooks, 2006; Masten, 2011), poverty (Brooks, 2006; Masten, 2011), racial and cultural discrimination (Brooks, 2006), war, terrorism and disasters (Masten, 2014), domestic violence and family psychopathology (Bowes \& Jaffee, 2013), child abuse (Masten, 2001), divorce (Masten et al., 1990), homelessness (Masten, 2001), low academic success and dropping out of school (Brooks, 2006). 
Protective Factors are those that contribute to attaining positive outcomes despite the risk factors involved (Brooks, 2006). Resilience is prevented due to risk factors and supported by protective factors (Zolkoski \& Bullock, 2012). Social competence, empathy, communication skills, humor, success in establishing relations with peers (Benard, 1991), problem solving skills (Benard, 1993; Masten \& Reed, 2002), autonomy, having a purpose, supporting familial environment, high expectations (Benard, 1993; Masten \& Reed, 2002), encouraging and warm family (Benard, 1993; Masten, 2014; Masten \& Coatsworth, 1998), self-efficacy (Masten \& Reed, 2002; Rutter, 1987), self-esteem (Rutter, 1987), self-regulation (Alvord \& Grados, 2005; Masten, 2014; Masten \& Coatsworth, 1998), humor (Masten \& Reed, 2002), an effective school environment (Benard, 1991; Masten \& Reed, 2002), emotion regulation skills (Masten, 2014), academic success (Masten \& Coatsworth, 1998) are protective factors. Protective factors are those that help children and adolescents cope with the difficulties they face and they should be evaluated within the framework of the developmental stage of the child and cultural elements (Alvord \& Grados, 2005).

Positive Outcome Masten (2001) emphasized that positive outcomes are as important as risk and protective factors. Positive outcomes are criteria used for assessing a good adaptation. Positive behaviors such as social and academic success, behaviors specific to the age and development period, happiness or life satisfaction, not having any undesired behaviors, not having any psychopathology, peer acceptance and positive friend relations, age-appropriate activities are positive outcomes. Moreover, fulfilling the age dependent developmental tasks is also defined as a positive outcome (Masten \& Reed, 2002).

The primary requirement of resilience is the presence of risk and protective factors for increasing positive outcomes or reducing negative outcomes (Fergus \& Zimmerman, 2005; Zolkoski \& Bullock, 2012). Hence, resilience focuses on understanding positive outcomes and healthy development instead of exposing risks; that is, it focuses on strengths instead of inadequacies (Luthar \& Cicchetti, 2000). It is thought that decreasing irrational beliefs of adolescents and improving their subjective well-being levels are important in developing positive results and decreasing negative results. Because the cognitive processes of adolescents who are faced with risk factors will come to the fore as they can cope with these risks. Irrational beliefs will increase the effects of risk factors as they cause the adolescent to see themselves, others and the world from a negative perspective. Similarly, the development and strengthening of protective factors will contribute to the increase of the subjective well-being level of adolescents and their satisfaction from life and thus to successfully fulfill their developmental tasks.

Cognitive-behavioral therapy (CBT) as evidence-based therapy with proven effectiveness is one of the most effective therapies of our day. CBT is a psychotherapy approach that is among the most frequently researched approaches among all psychotherapies which is also the first evidence-based psychotherapy approach (David et al., 2018). The effectiveness of CBT has been put forth in meta-analysis research carried out with children and adolescents during randomized controlled studies (Arnberg \& Öst, 2014; Lenz \& Hollenbaugh, 2015; McGuire et al., 2015; Scaini et al., 2016; Vigerland et al., 2016). CBT is a therapy that focuses on problem 
solving and which is defined in a short period of time. This model provides the counselee with an easy to understand treatment logic (Sungur, 1997).

It is accepted in CBT that the individual distorts the experienced life event or situation due to his/her cognitive infrastructure and hence leading to the emergence of automatic thoughts followed by the disruption of the individual's adaptation processes due to various negative emotions resulting in dysfunctional behaviors. It is accepted in CBT that these disrupted thoughts lead to the continuity of unassociated emotions which in turn abet the continuity of dysfunctional behaviors (Özdel, 2015). CBT is based on a structured and psycho-educational model. Homework assigned to the individual during and after the therapy sessions in order to enable them to take responsibility with an active role holds significant importance.Cognitive and behavioral strategies are used to ensure change. CBT is based on the assumption that behaviors can be regulated by restructuring the sentences used by the individual during internal speeches or thought of consciously/unconsciously (Corey, 2008). Hence, CBT makes us realize the structures of thinking that cause problems in the individual and to replace them with functional and flexible thoughts for strengthening the processes of adaptation. It can be observed when the protective factors of psychological resilience are examined that it includes factors such as self-efficacy, self-regulation, self-esteem, problem solving skill, cognitive flexibility, emotional regulation skills, coping skills, social support. Studies on psychological resilience emphasize the importance and strengthening of protective factors (Luthar \& Cicchetti, 2000). Therefore, it is observed that taking into consideration the non-functional thoughts, the process of cognitive restructuring and the ability to think more functionally and flexibly hold an important place for the protection and strengthening of protective factors. Therefore, it can be stated that CBT-based resilience programs are effective because they emphasize both cognitive processes and develop protective factors. When we consider the success of CBT in psychopathology, it is important to use it for increasing happiness, developing resilience and improving other positive characteristics (Padesky \& Mooney, 2012). Happer et al. (2017) emphasized that CBT that places coping skills at its center may be effective in improving resilience. Similarly, Dray et al. (2017) conducted a meta-analysis study for examining the effectiveness of resilience programs as a result of which it was reported that the use of CBT based approaches in reducing the symptoms of anxiety and depression in children and adolescents has been more effective. It is observed when the interventions and programs for improving psychological resilience in children are examined that CBT has frequently been selected as the foundation (Bastounis et al., 2016; Brunwasser et al., 2009; Brunwasser \& Gillham, 2018; Gillham et al., 2007, 2008; Happer et al., 2017).

School is one of the most important environmental factors in improving psychological resilience. Indeed, an effective school environment plays a protective role against various risks in the family and community (Brooks, 2006). For this purpose, school environments are places that can be used most effectively and functionally for improving psychological resilience. Adolescence is a critical period during whichsignificant changes occur in the lives of the individual and the foundations are laid for their future lives. The adolescent individual may live through various opportunities and experiences for growth, maturity, 
transformation and improvement while on the other hand they may also need to cope with problems that may have an impact on their academic, personal and social adaptation (Duru \& Arslan, 2014). According to various theorists such as Freud and Erikson, adolescence is a period of critical importance during which major developmental changes and stress inducing experiences related with development emerge. The changes that take place during this period along with the responses to stress and the adaptation displayed by the individual have a significant impact on the future developmental patterns of the individual. It has been observed that even though some adolescents are able to utilize coping and adaptation mechanisms more successfully during this period, some adolescents are not able to do so that sufficiently (Eminağaoğlu, 2006). For this reason, children and adolescents need a certain level of strength, skill and resilience in order to actively solve the problems they may encounter in all areas of their lives, establish healthy relationships with their environment and cope with difficult life events. In addition, it is also of critical importance that they develop the skills required to enable them to stand by themselves after their education period is over, transform into individuals with self-confidence who are able to utilize their problem solving and effective coping skills while also putting forth their creativity and in short becoming healthy adults.

Individuals in adolescence may become happy, successful and skilled individuals if they are able to control their emotions, thoughts and behaviors in a way to keep away from risky experiences (Tarhan, 2006). In addition, it is considered that individuals who are aware and able to control their structures of thinking can become psychologically more resilient if they are also able to increase their states of well-being. In the meantime, it is also possible for individuals who are psychologically resilient and who are conscious of their structures of thinking to contribute to their subjective well-being. Hence, it is considered important to carry out studies on resilience with regard to increasing the effectiveness of intervention and prevention studies in schools, societies and family services (Kumpfer, 1999).

It is considered that the increase in psychological resilience will enable high school students in their adolescence to develop a more positive perspective on life, to cope with the risk factors in their lives without leading to significant problems, to develop a more flexible system of thought and to continue their lives more strongly by coping more effectively with the problems they encounter at every period in their lives. For this purpose, it is thought that the present study will put forth significant findings with regard to improving the psychological resilience of all high school students with the utmost priority given to adolescents under risk. It is thought that the study results will be an important reference point with regard to studies carried out on adolescents by psychological counselors working at schools especially within the scope of preventive guidance along with many other fields. Also, the present study is considered as an important step for filling the gap with regard to the implementation of cognitive behavioral interventions in Turkey and attracting attention to improving psychological resilience via CBT method. Hence, the purpose of the present study was to examine to impact of cognitive-behavioral group psycho-education program on 
psychological resilience, irrational beliefs, and well-being. The following hypotheses will be tested in the study in accordance with the aforementioned objectives:

1. There will be a statistically significant difference between the psychological resilience levels of students in the experiment group subject to cognitive-behavioral group psycho-education program and those of the control group students who were not included in this program.

2. There will be a statistically significant difference between the irrational belief levels of students in the experiment group subject to cognitive-behavioral group psycho-education program and those of the control group students who were not included in this program.

3. There will be a statistically significant difference between the subjective wellbeing levels of students in the experiment group subject to cognitive-behavioral group psycho-education program and those of the control group students who were not included in this program.

4. The differences observed between the psychological resilience, irrational belief and subjective well-being levels of experiment group students subject to cognitive-behavioral group psycho-education program will continue throughout the five-month follow-up period.

\section{Methods}

\section{Design}

This is a study utilizing the experimental pattern for examining the impact of cognitive-behavioral group psycho-education program on psychological resilience, irrational beliefs and subjective well-being levels. A $2 \times 3$ mixed pattern with experiment and control groups and pre-test, post-test and follow-up measurements was used in the study (Büyüköztürk, 2016).

The independent variable of the study was cognitive-behavioral group psychoeducation program. Whereas the dependent variables of the study were psychological resilience, irrational beliefs and subjective well-being.

\section{Participants}

The study was carried out with 29 students selected from among 272 ninth grade students continuing their education at a Ministry of National Education high school in the province of Kahramanmaraş in Turkey. The control group was comprised of a total of 15 individuals with 8 females and 7 males, whereas the control group was comprised of a total of 14 individuals with 7 males and 7 females. The inclusion and exclusion criteria used in forming the research group are as follows:

\section{Inclusion Criteria:}

1. Being a 9th grade student at the selected school.

2. Having 3 or more risk factors in the Risk Determination List, 
3. Volunteering to participate in research.

\section{Exclusion Criteria:}

1. Getting psychological help,

2. Any organic, bipolar or psychotic disorder, substance abuse or suicide risk

3. Being diagnosed with PTSD as a result of childhood trauma

4. Use psychological treatment or psychiatric medication at the time of inclusion

\section{Measures}

\section{Resilience Scale}

The Resiliency Scale was developed by Gürgan (2006) for determining the psychological resilience levels of high students at the high school and university education levels. It was observed as a result of the factor analysis to determine the construct validity of the scale that 50 items are collected under 8 factors which explain $57.56 \%$ of the total variance. These factors were named as personal power $(15.86 \%)$, initiative $(8.67 \%)$, optimism $(7.86 \%)$, relationships (6.15\%), foresighted $(5.53 \%)$, purpose in life $(5.20 \%)$, leadership (4.03\%), investigative (2.41\%).Cronbach Alpha values were calculated separately for the first and second application for the same group ( 0.78 and 0.87 respectively) in order to carry out the internal consistency study for the Resiliency Scale (Gürgan, 2006).

\section{Irrational Beliefs Scale: Adolescent Form}

Irrational Beliefs Scale was initially developed by Türküm (2003) for measuring the level of irrational beliefs among university students. In the scale development process, three main sources of irrationality in Ellis's model (self-demand, demanding of other people and demanding about the world) were taken as basis. High scores from the scale indicate that irrational beliefs are high. A total score can be obtained from the scale. The scale developed for university students consists of a three-factor structure. The first factor, the "need for approval", includes irrational statements about approval. The second factor "interpersonal relationships" includes individuals' irrational beliefs about interpersonal relationships. The third factor is named as "I", which includes irrational beliefs about oneself (Türküm, 2003). The adolescent form of the same scale was also prepared by Türküm et al. (2005). In the version adapted to high school students, there are 5 factors. Examples of items are: "Mishaps always find me, I feel responsible when things go wrong, I cannot stand the absence of my loved ones, A person who is my friend is the one who can understand what he feels without saying, I always care about the opinions of others, I avoid criticizing people so as not to offend them, I can give up my wishes rather than hurt my relatives, Promises given must be kept". Since the adolescent form is evaluated on the total score, its sub dimensions are not named. The Irrational Beliefs 
Scale-Adolescent Form comprised of 16 items is a five-point Likert type. The highest and lowest scores that can be obtained from the scale are 80 and 16 respectively. Cronbach Alpha internal consistency coefficient was determined as 0.70 and splithalf test correlation was determined as $0.69(p<0.05)$ as a result of the reliability studies carried out for the scale. Item-total correlation coefficients were observed to vary between 0.20 and 0.41 (Türküm et al., 2005).

\section{Subjective Well-Being Scale-High School Form}

Developed by Tuzgöl-Dost (2004) for university students, the high school form of the Subjective Well-Being Scale was developed by (2005) with 37 items for application on high school students.Subjective Well-Being Scale-High School Form is comprised of various judgments on the areas that have an impact on the satisfaction of life of the individual as well as positive/negative expressions of emotion.It was determined as a result of the reliability studies that the Cronbach Alpha reliability coefficient of the scale is 0.91; Pearson Product Moments Correlation Coefficient was calculated as 0.82 following the test-retest application (Özen, 2005).

\section{The List of Determining Risk Factors}

The List of Determining Risk Factors was used in the present study for placing students with risk factors in experiment and control groups in order to examine psychological resilience. The List of Determining Risk Factors developed by Terzi (2008) as a result of a literature survey is comprised of 30 items and three domains. These include the individual domain (history of a chronic disease, low self-confidence), family domain (history of drug abuse among parents, domestic violence) and social domain (low socio-economic level, migration).

\section{Treatments}

\section{Definition of Cognitive-Behavioral Group Psycho-Education Program}

In this study, Cognitive-Behavioral Group Psycho-Education Program developed by Türk et al. (2015) was used. The primary aim of psycho-education program is to develop the psychological resilience of adolescents based on a cognitive behavioral approach. Cognitive-behavioral group psycho-education program focuses on the irrational beliefs of Ellis while also emphasizing the multiple choice and flexible thinking skills of Beck's methods and techniques, although the cognitive distortions were not measured in this study. The program is based on the combination of the theoretical perspective of CBT. Psycho-education has a psychological counselor manual. It is a fully structured program. The manual clearly puts forth how the implementer will proceed at each step.

First, the already existing psychological resilience programs were examined when developing the education program and as a result, the skills that should be included in the education program were determined. Accordingly, a framework was developed that was initially based on cognitive-behavioral strategies and cognitive 
restructuring. Taking into consideration the necessity of the cognitive restructuring process in order to improve psychological resilience of adolescents, these studies were given priority during the first five sessions of the program. It is aimed by way of implementing cognitive-behavioral strategies to ensure that adolescents are able to identify their own emotions and thoughts in addition to realizing the connections between emotions-thoughts and behaviors. It is especially aimed to provide a different perspective to adolescents with regard to themselves through the process of discovering rational and irrational thoughts. Psychological resilience education is comprised of 10 sessions. The first five sessions of cognitive-behavioral group psycho-education programfocuses on cognitive restructuring. The next five sessions include the most basicinternal and external protective factors regarding resilience. Cognitive restructuring is used at every stage of improving internal and external protective factors. Methods such as games, providing information, group sharing, role playing, group work and drama were used during this program based on ensuring that adolescents realize, use and develop their already existing potentials. Moreover, films and songs were used in order to attract the attention of adolescents and to establish communication through "their own language". The aim here is to ensure the permanence of acquired skills and to attract their attention (Türk et al., 2015). Based on this aim the psycho-educational program sessions presented in Table 1 were applied to the experimental group.

\section{The Control Condition}

Psychological support receiving status of the adolescents was considered as the control condition in the present study. School psychological counselors verified throughout the experimental procedure whether the adolescents in the experiment and control groups received any psychological support or not. Moreover, the adolescents in the experiment and control groups were evaluated with regard to the risks other than the risk factors selected in the risk identification list.

\section{Procedure}

Selecting the individuals for research applications via random method is one of the conditions of the experimental pattern (Hovardaoğlu, 2007). For this purpose, the List of Determining Risk Factors was applied on 272 students ongoing their education in the ninth grade prior to starting the psycho-education application (see Fig. 1). A total of 29 students who marked 3 and more risk factors from among the applied List of Determining Risk Factors were selected after which the students were numbered and their numbers were placed in a bag for separating the students into experiment-control groups randomly and without bias based solely on drawing numbers from the bag. Post-test application could not be carried out and was removed from the study since one individual from the control group left the school after the pretest application. Individual interviews were carried out with the students selected for the experiment group in order to ensure that the participants volunteer for their participation to the psycho-education sessions. In addition, informed consents were 
Table 1 Cognitive-behavioral group psycho-education program sessions

1 st session

2nd session identifying the emotions

3rd session identifying thoughts

4th session ABC model

5th session ability to change/flex thoughts

7 th session improving self-esteem

8th session skills of assertiveness
Meeting with the group members

Determining the rules with the group members

Identifying the personal goals in the group

Identifying the general goal of the group

Establishing mutual trust in the group by way of warmup activities

Assessment and summary of session

Identifying the emotions

Expressing the emotions

Realizing that it is possible to feel different emotions in the same situation

Realizing the relationship between emotions, thoughts and behaviors

Assessment and summary of session

Identifying irrational and rational thoughts

Realizing the characteristics of irrational thoughts

Realizing one's own irrational thoughts

Assessment and summary of session

Getting to know the ABC Model

Grasping the ABC model

Implementing the $\mathrm{ABC}$ model via examples

Implementing the ABC model via examples from one's own life

Assessment and summary of session

Ability to carry out Socratic questioning for irrational thoughts

Searching for proofs for irrational thoughts

Ability to conduct risk-benefit analysis for irrational thoughts

Assessment and summary of session

6th session improving communication skills Knowing the concept of empathy

Realizing the importance of empathy for interpersonal relations

Ability for self-expression during communication

Assessment and summary of session

Identifying positive traits

Identifying negative traits

Accepting one's own positive and negative traits

Ability to conduct a positive internal dialogue with one's own self

Assessment and summary of session

Identifying the concepts of avoidance, aggressiveness and assertiveness

Identifying the impacts of aggressive behaviors in interpersonal relations 
Table 1 (continued)

Discovering the irrational thoughts underlying non-asser-
tive behaviors
Ability to replace the irrational thoughts underlying non-
assertive behaviors with rational thoughts
Identifying the situations that require the individual to say
no
Knowing the methods of saying no
Assessment and summary of session
Identifying the methods used when coping with difficulties
Improving the methods used when coping with difficulties
Developing a personal strategy for struggling with difficul-
ties
Discovering the sources of social support when struggling
with difficulties
Establishing personal positive future expectations
Assessment and summary of session
Identifying the level at which they have reached the per-
sonal goals in the group
Assessing their use of the new thinking strategies for cop-
ing with difficulties
Assessment of the improvements attained with regard to
strategies for coping with difficulties
Assessment of the group process
Leaving the group with positive feelings
10th session general assessment and closures $\quad$

acquired from the families of the students. During the interviews, the students were informed on the duration of the psycho-education program, the location where the sessions will be held as well as the number of sessions and their schedule. Afterwards, the students in the experiment and control groups were subject to Resiliency Scale, Irrational Beliefs Scale-Adolescent Form and Subjective Well-Being Scale-High School Form.Cognitive Behavioral Approach Based Psycho-Education Program was applied by the first author on the experiment group for a period of 10 weeks (March 2017, June 2017). No procedure was performed for the control group. The scales were reapplied to the groups as post-test application at the end of the 10 weeks during which the experiment group was subject to the psycho-education program. Follow-up measurements were conducted on the experiment and control groups 5 months (October 2017) after the experimental procedure.

\section{Therapists}

The primary author of the study who conducted is a 26-year-old female. The author has completed her undergraduate and graduate education in the field of Psychological Counseling and Guidance. The author has been working as a psychological counselor for adolescents for five years. The primary author has completed the 


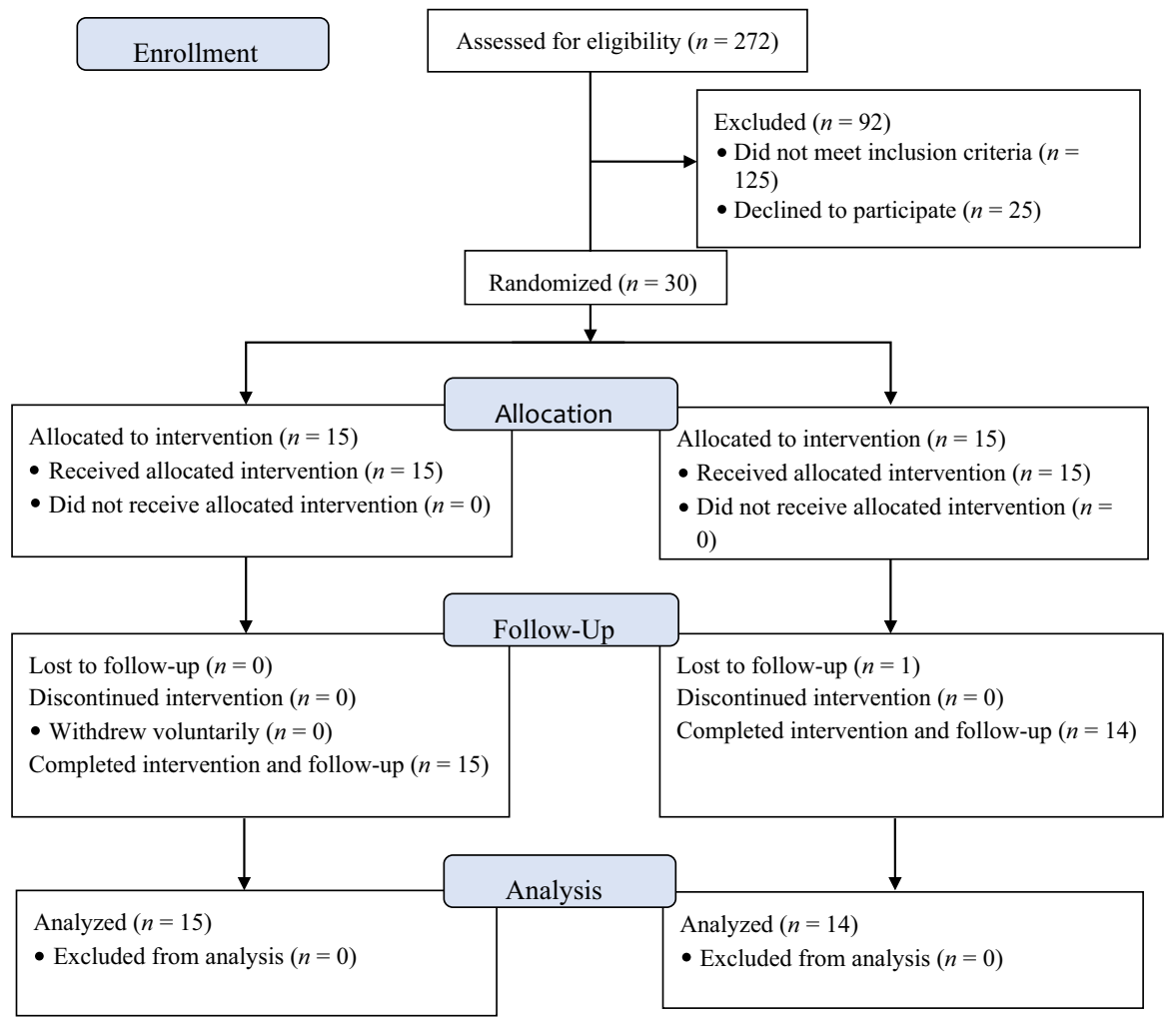

Fig. 1 Flow diagram for randomized controlled trials of cognitive behavioral based psycho-education groups for adolesencents

$450 \mathrm{~h}$ CBT training accredited and certified by the European Association for Behavioral and Cognitive Therapies (EABCT). The second author of the study provided supervision to the primary author during implementation. The Cognitive Behavioral Approach Based Group Psycho-Education has been developed by the team led by the second author. For this reason, supervision support was provided to the primary author. The second author provided training to the primary author regarding the skills and knowledge related with software usage. The checklist of the software manual was followed. The second author has completed her undergraduate, master's degree, doctorate and associate professorship in the field of Psychological Counseling and Guidance. In addition, the second author has also completed the $450 \mathrm{~h}$ CBT training accredited by the European Association for Behavioral and Cognitive Therapies (EABCT).

\section{Data Analysis}

The normality test of the data for the experiment and control groups was examined via Shapiro-Wilks during the study. Levene test was conducted prior to the analyses 
Table 2 Shapiro-Wilk results for all scales

\begin{tabular}{lllll}
\hline Scales & Measures & \multicolumn{4}{l}{ Shapiro-Wilk } \\
\cline { 3 - 5 } & & Statistic & SD & $p$ \\
\hline Resilience Scale & Pre-test & .975 & 29 & 0.690 \\
& Post-test & .962 & 29 & 0.360 \\
Irrational Reliefs Scale & Pre-test & .983 & 29 & 0.905 \\
& Post-test & .941 & 29 & 0.105 \\
Well-Being Scale & Pre-test & .981 & 29 & 0.866 \\
& Post-test & .987 & 29 & 0.967 \\
\hline
\end{tabular}

to examine whether the variances of the parametric test assumptions are homogeneous or not. Table 2 presents the Levene test and Shapiro-Wilk test results for each dependent variable.

As can be seen from Tables 2 and 3, the normality assumption has been met for the Resiliency Scale, Irrational Beliefs Scale and Subjective Well-Being Scale and that the variances are homogeneous.

Covariance analysis (ANCOVA) was used for determining whether there is a statistically significant between the dependent variable scores of the experiment and control groups. Whereas one way variance analysis (ANOVA) was used for repeated measurements in order to compare the repeated measurements of the experiment group.

Effect size was also calculated in the present study. While ANCOVA and ANOVA indicate whether there are statistically significant differences between the two groups or not, it does not provide information with regard to the size of this difference. Hence, it is also necessary to know the effect size in addition to statistical significance (Can, 2017). The most commonly used effect size statistics is the etasquare coefficient $\left(\eta^{2}\right)$. Eta-square puts forth the level of impact of the independent variable on the dependent variable. Eta-square $\left(\eta^{2}\right)$ values that range between 0.00 and 1.00 are interpreted as "small", "moderate" and "large" effect size respectively for 0.01, 0.06 and 0.14 (Büyüköztürk, 2016).

\section{Results}

The purpose of the present study was to examine the impact of cognitive-behavioral group psycho-education program on the psychological resilience, irrational beliefs and subjective well-being levels of adolescents.

Table 3 Levene test results for all scales

\begin{tabular}{llll}
\hline & Levene & SD1 & SD2 \\
\hline Resilience Scale & .170 & 1 & 27 \\
Irrational Reliefs Scale & .823 & 1 & 27 \\
Well-Being Scale & .490 & 1 & 27 \\
\hline
\end{tabular}


Table 4 Adjusted mean values for the resiliency scale, irrational beliefs scale and subjective well-being scale of the experiment and control groups calculated by keeping the post-test mean values and pre-test scores constant

\begin{tabular}{lllll}
\hline Scale & Groups & N & Mean & Adjusted mean \\
\hline Resilience Scale & Experiment & 15 & 3065 & 3067 \\
& Control & 14 & 2925 & 2924 \\
Irrational Reliefs Scale & Experiment & 15 & 3270 & 3328 \\
& Control & 14 & 3821 & 3760 \\
Well-Being Scale & Experiment & 15 & 3099 & 3078 \\
& Control & 14 & 3109 & 3132 \\
\hline
\end{tabular}

The mean and adjusted means for the experiment and control groups were first presented in Table 4 for the Resiliency Scale, Irrational Beliefs Scale-Adolescent Form and Subjective Well-Being Scale-High School Form.

Table 4 presents the ANCOVA results for the first hypothesis of the study with regard to whether the experiment and control group scores for the Resiliency Scale vary at a statistically significant level or not.

As can be seen in Table 5, a statistically significant difference was observed between the psychological resilience scores of adolescents in the experiment and control groups when the pre-test scores were fixed $\left(\mathrm{F}_{(1,28)}=8542, p<0.05\right.$, $\left.\eta^{2}=0.24\right)$. In conclusion, a statistically significant difference was observed between the psychological resilience scores of the control group and the experiment group which participated in the cognitive-behavioral group psycho-education program.

Table 6 presents the ANCOVA results for the second hypothesis of the study with regard to whether the experiment and control group scores for the Irrational Beliefs Scale vary at a statistically significant level or not.

It was concluded based on Table 6 that there is a statistically significant difference between the irrational beliefs scores of adolescents in the experiment and control groups at fixed pre-test score $\left(F_{(1,28)}=16,175, p<0.05, \eta^{2}=0.38\right)$. In conclusion, it was determined that there is a statistically significant difference

Table 5 ANCOVA results for the adjusted scores of the experiment and control groups obtained from the Resiliency Scale

Table 6 ANCOVA results for the adjusted scores of the experiment and control groups obtained from irrational Beliefs Scale

\begin{tabular}{llrllll}
\hline Source & Sum of square & $d f$ & Mean square & F & $p$ & $\eta^{2}$ \\
\hline Pre-test & .002 & 1 & .002 & .141 & 0.710 & \\
Group & .142 & 1 & .142 & 8.542 & 0.007 & .247 \\
Error & .432 & 26 & .017 & & & \\
Total & .575 & 28 & & & & \\
\hline
\end{tabular}

\begin{tabular}{llrllll}
\hline Source & Sum of square & $d f$ & Mean square & F & $p$ & $\eta^{2}$ \\
\hline Pre-test & 1.120 & 1 & 1.120 & 14.606 & 0.001 & \\
Group & 1.240 & 1 & 1.240 & 16.175 & 0.000 & .384 \\
Error & 1.994 & 26 & .077 & & & \\
Total & 5.309 & 28 & & & & \\
\hline
\end{tabular}


between the irrational beliefs scores of the experiment group that took part in the cognitive-behavioral group psycho-education program in comparison with those of the control group.

Table 7 presents the ANCOVA results for the third hypothesis of the study with regard to whether the experiment and control group scores for the Subjective WellBeing Scale vary at a statistically significant level or not.

As can be seen in Table 7, a statistically significant difference was not observed between the subjective well-being scores of adolescents in the experiment group who took part in the cognitive behavioral approach based psycho-education program and the adolescents in the control group who did not take part in this education $\left(\mathrm{F}_{(1,28)}=0.274, p>0.05, \eta^{2}=0.01\right)$.

ANOVA test was performed for each dependent variable for the fourth hypothesis of the study. Accordingly, a statistically significant difference was determined between the Resiliency Scale pre-test, post-test and follow-up test scores $\left(F_{(2,28)}=16,437, p<0.05, \eta^{2}=0.54\right)$. On the other hand, the differences between the pre-test-post-test and pre-test-follow-up test scores were observed to be statistically significant, while the difference between the post-test-follow-up test scores was not observed to be statistically significant. This finding indicates that the psychological resilience levels of the students in the experiment group increased at a statistically significant level after the application and that the psychological resilience levels do not differ from the findings obtained during the follow-up studies carried out five months later. Similarly, a statistically significant difference was determined between the Irrational Beliefs Scale pre-test, post-test and follow up test scores $\left(F_{(2,28)}=14,804, p<0.05, \eta^{2}=0.51\right)$. On the other hand, the differences between pre-test-post-testand pre-test-follow-up test scores were observed to be statistically significant, while the difference between the post-test-follow-up test scores was not observed to be statistically significant. This finding indicates that the irrational belief levels of the students decreased at a statistically significant level following the application and that the irrational belief levels did not differ from the findings obtained during the follow-up measurements obtained five months later. Finally, a statistically significant difference could not be observed between the Subjective Well-Beingpretest, post-testand follow-up test scores $\left(\mathrm{F}_{(2,28)}=0.084, p>0.05, \eta^{2}=0.00\right)$.

Table 7 ANCOVA results for the adjusted scores of the experiment and control groups obtained from well-beimg scale

\begin{tabular}{llrllll}
\hline Source & Sum of square & $d f$ & Mean square & \multicolumn{1}{l}{ F } & \multicolumn{1}{l}{$p$} & $\eta^{2}$ \\
\hline Pre-test & 1.076 & 1 & 1.076 & 13.909 & 0.001 & \\
Group & .021 & 1 & .021 & .274 & 0.605 & .010 \\
Error & 2.012 & 26 & .077 & & & \\
Total & 3.088 & 28 & & & & \\
\hline
\end{tabular}




\section{Discussion}

The impacts of cognitive-behavioral group psycho-education program on the psychological resilience levels, irrational beliefs and subjective well-being levels of adolescents were examined in the present study. Accordingly, it was concluded that there is a statistically significant increase in the psychological resilience levels of the adolescents who took part in cognitive-behavioral group psycho-education program. It was observed as a result of a literature survey that Dray et al. (2015) carried out a study on the impacts of general resilience interventions applied at school environment as a result of which it was determined that these intervention programs are effective in reducing the mental health problems of children and adolescents. Similarly, Sankaranarayanan and Cycil (2014) carried out a study examining the impact of resilience program on Indian children as a result of which it was reported that the pessimistic style children used to describe themselves decreased in children who took part in this education while the optimistic style increased. Gillham et al. (2006) carried out a study for examining the impact of the resilience program on the depression levels of male adolescents in which it was concluded that the education is not effective in preventing depressive disorder, but that it is effective against multiple disorders in which depression, anxiety and adaptive disorders are observed together. Cutuli et al. (2013) carried out a study in which the resilience program reduced the internalizing symptoms of adolescents according to the statements of families. Pickering (2015) put forth as a result of a study on the impact of group education on resilience that group education increased the resilience of students. Kurtoğlu (2013) determined during a study on the effects of cognitive behavioral approach-based psycho-education program on emotional resilience in primary school first grade students that there is a statistically significant increase in the emotional resilience levels of the students. Similarly, Akça Koca and Erden (2018) determined in their study that cognitive behavior approach-based group psychological counseling program increased the psychological resilience of adolescents. It is considered that the findings of this and other studies on the effectiveness of cognitive behavioral approachbased intervention programs on psychological resilience will guide the implementers as well as researchers.

Similar to the results of this study, it was determined that the CBT-based Penn Resilience Program, which was applied over a period of approximately 30 years, was effective in reducing the depressive symptoms of children and adolescents (Brunwasser \& Gillham, 2018; Cutuli et al., 2013; Gillham et al., 2007, 2012). In addition, the CBT-based resilience strengthening program for children and adolescents can help reduce emotional and behavioral problems of children and adolescents with ADHD (Senior et al., 2020), reduce anxiety and depressive symptoms (Watson et al., 2014), and improve emotion regulation skills (Rich et al., 2019) has been found to be effective. Similarly, Happer et al. (2017) found that the trauma-focused CBTbased resilience program was effective in reducing children's traumatic stress and depression symptoms. When all research results are evaluated together, it is possible to state that CBT-based resilience programs are effective in reducing the psychopathological symptoms of children and adolescents and increasing their resilience. 
Adolescence is a critical period during which the child experiences a multidimensional transformation and the adolescent takes steps for his/her future life (Duru \& Arslan, 2014). During this period, it is expected from the child to improve his/ her perception on identity and to complete his/her identity achievement. In addition, adolescence is a period during which from a cognitive perspective the individual enters a period of abstract thinking while trying to cope with the ongoing biological, psychological and social changes (Duru \& Arslan, 2014; Santrock, 2012). Cases such as hopelessness, negative attitude towards himself/herself, the environment and life in general along with domestic conflicts/opposition against authority can be observed in adolescents during this period (Aydın, 2005). However, it has been put forth in various studies that it is possible to strengthen the coping skills of adolescents by way of cognitive behavioral interventions based on questioning and transforming the cognition of individuals on the ongoing events (Akça Koca \& Erden, 2018; Kurtoğlu, 2013; Padesky \& Mooney, 2012; Stallard et al., 2005). Thus, while on the one hand psychological resilience is increased, on the other hand it is possible to render the perception of the individual on himself/herself, the environment and the world in general more realistic and positive through the assessment of their cognitive structures. As such, it is possible to contribute to protecting the mental health of the individuals as well as the society.

It was concluded as a result of the present study that the irrational beliefs decreased at a statistically significant level in adolescents who took part in the cognitive-behavioral group psycho-education program. Howard (2014) carried out a study on the effects of psychological resilience program on pre-adolescent children in primary school environment in which it was determined that the program led to a decrease in the automatic negative thoughts of the children (Altun, 2006; Bacakoğlu, 2002; Buğa \& Hamamcı, 2016; Çivitci, 2003; Dray et al., 2015; Howard, 2014; Karagöz, 2011; Şahan Yılmaz \& Duy, 2013; Ulusoy \& ve Duy, 2013; Tekgül, 2015). Türk et al. (2018) performed a meta-analysis study as a result of which it was concluded that cognitive behavioral approach based group interventions are effective against the dysfunctional thoughts of children and adolescents. When considered from a cognitive behavioral approach perspective, noticing dysfunctional thoughts, transforming them and attaining a more flexible way of thinking is important since it also forms the foundation of the theory as well.

It has been put forth as another finding of the study that there is not a statistically significant difference between the subjective well-being levels of adolescents who took part in cognitive-behavioral group psycho-education program and the subjective well-being levels of adolescents in the control group.It was observed when concepts related with subjective well-being were examined that there are findings indicated that it is related with the control and attention of the parents (Özdemir, 2012), gender (Kasapoğlu \& Kış, 2016), personality traits (Compton, 2000; Eryılmaz \& Ercan, 2016), family environment (Eryılmaz, 2011), bonding with peers and parents (Baytemir, 2016), optimism tendency (Eryllmaz \& Atak, 2011), extroversion (Eryılmaz \& Ögüulmüş, 2010), satisfaction with physical appearance (Tuzgöl-Dost, 2006), internal and external motivation (Eryılmaz, 2010), competence and optimism (Ben-Zur, 2003), social support (Yalçın, 2015), academic, social and emotional self-efficacy (Telef \& Ergün, 2013) and social appearance anxiety (Seki \& Dilmaç, 
2015). Hence, it can be considered that the program is not effective by itself due to the multivariate characteristic of subjective well-being. Since the program used in the study is aimed at improving the psychological resilience characteristics of adolescents, it is considered that the activities in the program are not intended to improve subjective well-being. Therefore, it is thought that the program is insufficient for improving subjective well-being levels of adolescents.

The final conclusion of the study is important for putting forth that cognitivebehavioral group psycho-education program is effective in increasing the psychological resilience levels of the adolescents, that the decrease in the irrational beliefs of the adolescents continues during the follow-up measurements and that the skills and awareness levels acquired by the adolescents continue throughout the follow-up period.

In conclusion, school is an important external factor forpsychological resilience. Schools have many important duties for increasing the factors that are considered as indicators of psychological resilience in students.School is one of the most important environmental factors in improving psychological resilience. Indeed, an effective school environment plays a protective role against various risks in the family and community (Brooks, 2006). For this purpose, school environments are places that can be used most effectively and functionally for improving psychological resilience. Thus, the psychological resilience training programs applied at schools are considered to be effective in improving the psychological resilience of adolescents and children. For this purpose, it is considered that the psychological resilience education programs applied at schools are effective in improving the psychological resilience levels of adolescents and children. Family, school and society make up the three primary bases of support systems. It is considered that the effects of systematic education programs that enable the students to realize and improve their psychological resilience at schools in addition to supporting them will be observed in the long run (Türk et al., 2015).

It is aimed by way of psychological resilience education programs to improve and develop the internal and external protective factors of adolescents. It is observed when the concept of resilience and the factors that have an impact on resilience are examined that adolescents may cope with difficult life events in a more positive and successful manner if they acquire certain skills. This is especially important within the scope of developmental and preventive guidance emphasized with regard to psychological counseling and guidance services. Hence, it is observed that the implementation of cognitive behavioral approach-based resilience improvement programs by psychological counselors at schools is important. It is also necessary to indicate this: Covid-19 pandemic is a serious and difficult life event for adolescents as well as for all other individuals. In addition to the significant adverse effects on health of the virus; its indirect impacts such as the quarantine processes, distancing from the school, social isolation, and remote education are also observed to cause significant difficulties for adolescents. Thus, it is considered that improving the resilience of the adolescents during this process will contribute to helping them overcome this period in a healthy, compatible and successful manner. It may be suggested to the guidance services at the schools to implement such resilience interventions either online or via face-to-face applications. 
The present study on the effects of cognitive-behavioral group psycho-education programon adolescents has various limitations. A new program was not developed for psychological resilience in this study and the effects of an already existing program were examined. In addition, the present study has been carried out at a school in Turkey. Hence, the results can be generalized by carrying out the study with a larger study group. The present study has focused on the impacts of psycho-education by way of the resilience, irrational beliefs and subjective well-being levels of adolescents. Moreover, it may also be suggested to examine the impacts of other positive outcomes (academic success, happiness, life satisfaction, peer acceptance, developmental tasks etc.). The present study does not include a placebo group. A study can be designed with a placebo group for eliminating the placebo effect.

Funding This study was no funded.

\section{Declarations}

Conflict of interest The authors declare that they have no conflict of interest.

Ethical standards The researchers received permission from Social Sciences Ethics Committee to conduct the research. In addition, permission was obtained from the Provincial Directorate of National Education for the research. The researchers adhered to the established principles and codes of conduct the American Psychological Association (2010) and also followed the Declaration of Helsinki. Participants and their families completed the informed consent form designed by the researchers.

\section{References}

Akça Koca, D., \& Erden, S. (2018). The effect of cognitive-behavioral group counseling on psychological resilience and level of humor in adolescents. Life Skills Journal of Psychology, 2(3), 61-72.

Altun, E. (2006). The effect of rational emotional-based safety education on the irrational belief and security levels of fifth grade students in primary education. Unpublished master's thesis, Gazi University.

Alvord, M. K., \& Grados, J. J. (2005). Enhancing resilience in children: A proactive approach. Professional Psychology: Research and Practice, 36(3), 238-245. https://doi.org/10.1037/0735-7028.36.3. 238.

Arnberg, A., \& Öst, L. G. (2014). CBT for children with depressive symptoms: A meta-analysis. Cognitive Behaviour Therapy, 43(4), 275-288. https://doi.org/10.1080/16506073.2014.947316.

Aydın, B. (2005). Çocuk ve Ergen Psikolojisi. Atlas Pub.

Bacakoğlu, H. A. (2002). The effect of rational emotional education on the development of self-concept and rational thinking in children who do not see. Unpublished doctoral thesis, İstanbul University.

Bastounis, A., Callaghan, P., Banerjee, A., \& Michail, M. (2016). The effectiveness of the Penn Resiliency Programme (PRP) and its adapted versions in reducing depression and anxiety and improving explanatory style: A systematic review and meta-analysis. Journal of Adolescence, 52, 37-48. https://doi.org/10.1016/j.adolescence.2016.07.004.

Baytemir, K. (2016). The mediation of interpersonal competence in the relationship between parent and peer attachment and subjective well-being in adolescence. Education \& Science, 41(186), 69-91. https://doi.org/10.15390/EB.2016.6185.

Ben-Zur, H. (2003). Happy adolescents: The link between subjective well-being, internal resources and parental factors. Journal of Youth and Adolescence, 32(2), 67-79. https://doi.org/10.1023/A:10218 64432505 . 
Benard, B. (1991). Fostering resiliency in kids: Protective factors in the family, school, and community. Western Center for Drug-Free Schools and Communities.

Benard, B. (1993). Fostering resiliency in kids. Educational Leadership, 51(3), 44-48.

Bowes, L., \& Jaffee, S. R. (2013). Biology, genes, and resilience: Toward a multidisciplinary approach. Trauma, Violence, \& Abuse, 14(3), 195-208.

Brooks, J. E. (2006). Strengthening resilience in children and youths: Maximizing opportunities through the schools. Children \& Schools, 28(2), 69-76.

Brunwasser, S. M., \& Gillham, J. E. (2018). Identifying moderators of response to the Penn Resiliency Program: A synthesis study. Prevention Science, 19(1), 38-48. https://doi.org/10.1007/ s11121-015-0627-y.

Brunwasser, S. M., Gillham, J. E., \& Kim, E. S. (2009). A meta-analytic review of the Penn Resiliency Program's effect on depressive symptoms. Journal of Consulting and Clinical Psychology, 77(6), 1042-1054. https://doi.org/10.1037/a0017671.

Buğa, A., \& Hamamcı, Z. (2016). The effect of web-based interactive and traditional psychoeducational programs based on cognitive behavioral approach on children's cognitive errors and psychological symptoms. Gaziantep University Journal of Social Sciences, 15(3), 783-809.

Büyüköztürk, Ş. (2016). Sosyal Bilimler İçin Veri Analizi El Kitabı: İstatistik, Araştırma Deseni. SPSS Uygulamaları ve Yorum.

Can, A. (2017). Bilimsel Veri Analizinde Nicel Veri Analizi. Pegem Akademi Pub.

Çivitci, A. (2003). The effect of rational emotional education on the irrational belief, constant anxiety and logical decision-making levels of primary school students. Unpublished doctoral thesis, Gazi University.

Compton, W. C. (2000). Meaningfulness as a mediator of subjective well-being. Psychological Reports, 87(1), 156-160. https://doi.org/10.2466/PR0.87.5.156-160.

Corey, G. (2008). Psikolojik Danışma, Psikoterapi Kuram ve Uygulamaları. Ankara: Mentis Yayıncılık.

Cutuli, J. J., Gillham, J. E., Chaplin, T. M., Reivich, K. J., Seligman, M. E. P., Gallop, R. J., Abenavoli, R. M., \& Freres, D. R. (2013). Preventing adolescents' externalizing and internalizing symptoms: Effects of the Penn Resiliency Program. The International Journal of Emotional Education, 5(2), 67-79.

David, D., Cristea, I., \& Hofmann, S. G. (2018). Why cognitive behavioral therapy is the current gold standard of psychotherapy. Frontiers in Psychiatry, 9(4), 1-3. https://doi.org/10.3389/fpsyt.2018. 00004.

Dray, J., Bowman, J., Campbell, E., Freund, M., Wolfenden, L., Hodder, R. K., et al. (2017). Systematic review of universal resilience-focused interventions targeting child and adolescent mental health in the school setting. Journal of the American Academy of Child \& Adolescent Psychiatry, 56(10), 813-824. https://doi.org/10.1186/s13643-015-0172-6.

Dray, J., Bowman, J., Wolfenden, L., Campbell, E., Freund, M., Hodder, R., \& Wiggers, J. (2015). Systematic review of universal resilience interventions targeting child and adolescent mental health in the school setting: review protocol. Systematic Reviews Journal, 4, 186. https://doi.org/10.1186/ s13643-015-0172-6.

Duru, E., \& Arslan, G. (2014). Girl adolescents who run away from home to get married: A phenomenological study. Turkish Psychological Counseling and Guidance Journal, 5(41), 36-48.

Eminağaoğlu, N. (2006). Resilience in street children living in difficult conditions. Unpublished doctoral thesis, İzmir: Ege University.

Eryılmaz, A. (2010). The relationship between using of subjective well being increasing strategies and academic motivation in adolescence. Journal of Clinic Psychiatry, 13, 77-84.

Eryilmaz, A. (2011). The relationship between adolescents' subjective well-being and positive expectations towards future. The Journal of Psychiatry and Neurological Sciences, 24, 209-215. https://doi. org/10.5350/DAJPN2011240306.

Eryılmaz, A., \& Atak, H. (2011). The relationships between adolescent subjective wellbeing, self-esteem and optimism. Electronic Journal of Social Sciences, 10(37), 170-181.

Eryilmaz, A., \& Ercan, L. (2016). Investigating of the subjective well-being based on gender, age and personality traits. Turkish Psychological Counseling and Guidance Journal, 4(36), 139-151.

Eryılmaz, A., \& Öğülmüş, S. (2010). Subjective well-being and big five personality model at adolescence. Ahi Evran University Jornal of Education Faculty, 11(3), 189-203.

Fergus, S., \& Zimmerman, M. A. (2005). Adolescent resilience: A framework for understanding healthy development in the face of risk. Annual Review of Public Health, 26, 399-419. https://doi.org/10. 1146/annurev.publhealth.26.021304.144357. 
Gillham, J. E., Brunwasser, S. M., \& Freres, D. R. (2008). Preventing depression in early adolescence: The Penn Resiliency Program. In J. R. Z. Abela \& B. L. Hankin (Eds.), Handbook of depression in children and adolescets. (1st ed., pp. 309-332). The Guildford Press.

Gillham, J. E., Hamilton, J., Freres, D. R., Patton, K., \& Gallop, R. (2006). Preventing depression among early adolescents in the primary care setting: A randomized controlled study of the penn resiliency program. Journal of Abnormal Child Psychology, 34(2), 203-219. https://doi.org/10.1007/ s10802-007-9212-6.

Gillham, J. E., Reivich, K. J., Brunwasser, S. M., Freres, D. R., Chajon, N. D., Kas-Macdonald, V. M., Chaplin, T. M., Abenavoli, R. M., Matlin, S. L., Gallop, R. J., \& Seligman, M. E. P. (2012). Evaluation of a group cognitive-behavioral depression prevention program for young adolescents: A randomized effectiveness trial. Journal of Clinical Child \& Adolescent Psychology, 41(5), 621-639. https://doi.org/10.1080/15374416.2012.706517.

Gillham, J. E., Reivich, K. J., Freres, D. R., Chaplin, T. M., Shatté, A. J., Samuels, B., Elkon, A. G. L., Litzinger, S., Lascher, M., Gallop, R., \& Seligman, M. E. P. (2007). School-based prevention of depressive symptoms: A randomized controlled study of the effectiveness and specificity of the penn resiliency program. Journal of Consulting and Clinical Psycholog, 75(1), 9-19. https:// doi.org/10.1037/0022-006X.75.1.9.

Gürgan, U. (2006). The effect of group counseling on the resilience of university students. Unpublished doctoral thesis, Ankara University.

Happer, K., Brown, E. J., \& Sharma-Patel, K. (2017). Children's resilience and trauma-specific cognitive behavioral therapy: Comparing resilience as an outcome, a trait, and a process. Child Abuse \& Neglect, 73, 30-41. https://doi.org/10.1016/j.chiabu.2017.09.021.

Hovardaoğlu, S. (2007). Davranış Bilimleri İçin Araştırma Teknikleri. Ankara: Hatiboğlu Yayınları.

Howard, M. J. (2014). An evaluation of the pennresiliency program for disruptive preadolescents in an elementary school setting. A dissertation proposal. Liberty University, Lynchburg.

Karagöz, Y. (2011). Investigation of the effect of positive thinking education program on future optimism, depression and cognitive distortion levels of adolescents. Unpublished master's thesis, Dokuz Eylül University.

Kasapoğlu, F., \& K1ş, A. (2016). Investigating the subjective well-being in terms of gender: A metaanalysis. Mersin University Journal of the Faculty of Education, 12(3), 770-782.

Kumpfer, K. L. (1999). Factors and processes contributingto resilience: the resilience framework. In M. D. Glantz J. L. Johnson, (Eds), Resilience and development: Positive life adaptations (pp. 179-224). Kluwer Academic/Plenum Publishers.

Kurtoğlu, G. (2013). The effect of cognitive behavioral approach based group psycho-education on the levels of emotional resilience, social skills-school adaptation and self-esteem of primary school primary school students. Unpublished doctoral thesis, Ege University.

Lenz, A. S., \& Hollenbaugh, K. M. (2015). Meta-analysis of trauma-focused cognitive behavioral therapy for treating PTSD and co-occurring depression among children and adolescents. Counseling Outcome Research and Evaluation, 6(1), 18-32.

Luthar, S. S., \& Cicchetti, D. (2000). The construct of resilience: Implications for interventions and social policies. Development and Psychopathology, 12(4), 857-885. https://doi.org/10.1017/ s0954579400004156.

Luthar, S. S., Cicchetti, D., \& Becker, B. (2000). The construct of resilience: A critical evaluation and guidelines for future work. Child Development, 71(3), 543-562. https://doi.org/10.1111/14678624.00164 .

Masten, A. S. (2001). Ordinary magic: Resilience processes in development. American Psychologist, 56(3), 227-238. https://doi.org/10.1037/0003-066X.56.3.227.

Masten, A. S. (2011). Resilience in children threatened by extreme adversity: Frameworks for research, practice, and translational synergy. Development and Psychopathology, 23(2), 493506. https://doi.org/10.1017/S0954579411000198.

Masten, A. S. (2014). Ordinary magic: Resilience processes in development. (1st ed.). The Guildford Press.

Masten, A. S., Best, K. M., \& Garmezy, N. (1990). Resilience and development: Contributions from the study of children who overcome adversity. Development and Psychopathology, 2(4), 425444. https://doi.org/10.1017/S0954579400005812.

Masten, A. S., \& Coatsworth, J. D. (1998). The development of competence in favorable and unfavorable environments: Lessons from research on successful children. American Psychologist, 53(2), 205-220. https://doi.org/10.1037//0003-066x.53.2.205. 
Masten, A. S., \& Gewirtz, A. H. (2006). Resilience in development: The importance of early childhood. In R. E. Tremblay, R. G. Barr, \& R. D. Peters (Eds.), Encyclopedia on early childhood development. (pp. 1-6). Centre of Excellence for Early Childhood Development.

Masten, A. S., \& Reed, M. G. (2002). Resilience in development. In C. R. Snyder \& S. J. Lopez (Eds.), Handbook of positive psychology. (1st ed., pp. 74-88). Oxford University Press.

McGuire, J. F., Piacentini, J., Lewin, A. B., Brennan, E. A., Murphy, T. K., \& Storch, E. A. (2015). A meta-analysis of cognitive behavior therapy and medication for child obsessive-compulsive disorder: Moderators of treatment efficacy, response, and remission. Depression and Anxiety, 32(8), 580-593. https://doi.org/10.1002/da.22389.

Özdel, K. (2015). From past to present cognitive bahavioral therapies: Theory and practice. Türkiye Klinikleri J Psychiatry-Special Topics, 8(2), 10-20.

Özdemir, Y. (2012). Examining the subjective well-being of adolescents in terms of demographic variables, parental control, and parental warmth. Education and Science, 37(165), 20-33.

Özen, Ö. (2005). Subject well-being among adolescents. Unpublised master thesis, Hacettepe University.

Padesky, C. A., \& Mooney, K. A. (2012). Strengths-based cognitive-behavioural therapy: A four-step model to build resilience. Clinical Psychology and Psychotherapy, 19(4), 283-290. https://doi. org/10.1002/cpp.1795.

Pickering, C. E. (2015). Student resiliency: a mixed methods analysis of counseling group effects. A dissertation proposal. Maryland University.

Rich, B. A., Shiffrin, N. D., Cummings, C. M., Zarger, M. M., Berghorst, L., \& Alvord, M. K. (2019). Resilience-based intervention with underserved children: Impact on self-regulation in a randomized clinical trial in schools. International Journal of Group Psychotherapy, 69(1), 30-53. https://doi. org/10.1080/00207284.2018.1479187.

Rutter, M. (1987). Psychosocial reslience and protective mechanisms. American Journal of Orthopsychiatry, 57(3), 316-331. https://doi.org/10.1111/j.1939-0025.1987.tb03541.x.

Şahan-Yılmaz, B., \& Duy, B. (2013). Effectiveness of a psycho-education application on self-esteem and irrational beliefs of female college students. Turkish Psychological Counseling and Guidance Journal, 4(39), 68-81.

Sankaranarayanan, A., \& Cycil, C. (2014). Resiliency training in Indian children: A pilot investigation of the penn resiliency program. International Journal of Environmental Research and Public Health, 11(4), 4125-4139. https://doi.org/10.3390/ijerph110404125.

Santrock, J. W. (2012). Ergenlik. (D. M. Siyez, Çeviri editörü). Nobel Pub.

Scaini, S., Belotti, R., Ogliari, A., \& Battaglia, M. A. (2016). Comprehensive meta-analysis of cognitive-behavioral interventions for social anxiety disorder in children and adolescents. Journal of Anxiety Disorders, 42, 105-112. https://doi.org/10.1016/j.janxdis.2016.05.008.

Seki, T., \& Dilmaç, B. (2015). Predictor relationships between the values the adolescents have and their levels of subjective well-being and social appearance anxiety: A model proposal. Educaiton \& Science, 40(179), 57-67. https://doi.org/10.15390/EB.2015.3663.

Senior, C. J., Godovich, S. A., Habayeb, S., Alvord, M. K., \& Rich, B. A. (2020). The effects of a resilience-based group intervention for youth with ADHD. Journal of Child and Adolescent Counseling, 1-15. https://doi.org/10.1080/23727810.2020.1719353.

Stallard, P., Simpson, N., Anderson, S., Carter, T., Osborn, C., \& Bush, S. (2005). An evaluation of the FRIENDS programme: A cognitive behaviour therapy intervention to promote emotional resilience. Archives of Disease in Childhood, 90, 1016-1019. https://doi.org/10.1136/adc.2004. 068163.

Sungur, M. Z. (1997). Bilişsel-davranışçı terapilerin gelişim öyküsü. In Tangör, A. (Ed.) Psikoterapiler El Kitabı. Ege Psikiyatri Sürekli Yayınları. 50-66.

Tarhan, N. (2006). Mutluluk psikolojisi: Stresi mutluluğa dönüşürmek. Timaş Pub.

Tekgül, N. (2015). Anxiety level, academic success and cognitive errors and their interaction with cognitive-oriented psychoeducation program during adolescence. Unpublished master's thesis, Maltepe University.

Telef, B. B., \& Ergün, E. (2013). Self-efficacy as a predictor of high school students' subjective wellbeing. Journal of Theoretical Educational Science, 6(3), 423-433. https://doi.org/10.5578/keg. 5955.

Terzi, Ş. (2008). The relationships between resilience and internal protective factors in university students. Hacettepe University Journal of Education, 35(35), 297-306. 
Türk, F., Buğa, A., Çekiç, A., \& Hamamcı, Z. (2018). The effects of the cognitive-behavioral approach-based group interventions on children's and adolescents' dysfunctional thoughts: A meta-analytic study. Turkish Psychological Counseling and Guidance Journal, 8(49), 45-61.

Türk, F., Türkmen, C., Oğuz, B., Satıcı, B., Kurumuş, Y., Başol, N. \& Gümüş, B. (2015). Ergenler için yılmazlık eğitimi psikolojik danışman el kitabı. Denizli Rehberlik ve Araştırma Merkezi Psikoeğitim Serisi.

Türküm, A. S. (2003). The development of irrational belief scale and studies of minimizing the number of items. Turkish Psychological Counseling and Guidance Journal, 2(19), 41-47.

Türküm, A. S., Balkaya, A., \& Karaca, E. (2005). Adapting the irrational belief scale to high school students; validity and reliability studies. Turkish Psychological Counseling and Guidance Journal, 3(23), 77-85.

Tuzgöl-Dost, M. (2004). Subjective well-being among university students. Unpublished doctoral thesis, Hacettepe University.

Tuzgöl-Dost, M. (2006). Subjective well-being among university students. Hacettepe University Journal of Education, 31, 188-197.

Ulusoy, Y., \& ve Duy, B. (2013). Effectiveness of a psycho-education program on learned helplessness and irrational beliefs. Educational Secience: Theory \& Practice, 13(3), 1431-1446. https:// doi.org/10.12738/estp.2013.3.1469.

Watson, C. C., Rich, B. A., Sanchez, L., O’Brien, K., \& Alvord, M. K. (2014). Preliminary study of resilience-based group therapy for improving the functioning of anxious children. In Child \& Youth Care Forum, 43(3), 269-286. https://doi.org/10.1007/s10566-013-9238-6.

Vigerland, S., Lenhard, F., Bonnert, M., Lalouni, M., Hedman, E., Ahlen, J., Olen, O., Serlachius, E., \& Ljotsson, B. (2016). Internet-delivered cognitive behavior therapy for children and adolescents: A systematic review and meta-analysis. Clinical Psychology Review, 50, 1-10. https://doi. org/10.1016/j.cpr.2016.09.005.

Yalçın, İ. (2015). Relationships between well-being and social support: A meta analysis of studies conducted in Turkey. Turkish Journal of Psychiatry, 26(1), 21-32. https://doi.org/10.5080/u7769.

Zolkoski, S. M., \& Bullock, L. M. (2012). Resilience in children and youth: A review. Children and Youth Services, 34(12), 2295-2303. https://doi.org/10.1016/j.childyouth.2012.08.009.

Publisher's Note Springer Nature remains neutral with regard to jurisdictional claims in published maps and institutional affiliations. 